\title{
Ogilvie syndrome presenting with septic shock
}

\author{
Serkan Özsoylu, Başak Nur Akyıldız, Adem Dursun \\ Division of Pediatric Intensive Care Unit, Department of Pediatrics, Erciyes University Faculty of Medicine, Kayseri, \\ Turkey.E-mail: sozsoylu@hotmail.com \\ Received: 14th April 2017, Revised: 29th May 2017, Accepted: 4th June 2017
}

\begin{abstract}
SUMMARY: Özsoylu S, Akyıldız BN, Dursun A. Ogilvie syndrome presenting with septic shock. Turk J Pediatr 2018; 60: 225-227.

Acute colonic pseudo-obstruction (ACPO) is also known as Ogilvie's. We report a 10 -year-old child with an unremarkable past history who presented with septic shock including hypotension, prolonged capillary refill time, decreased urine output $(<0.5 \mathrm{ml} / \mathrm{kg} / \mathrm{h})$, metabolic acidosis, liver failure, respiratory failure. The symptoms resolved with supportive therapy. In our patient septic shock contributed to Ogilvie syndrome. Although it is a rare condition in pediatric population, pediatricians should be aware of children with abdominal distention; supportive management is successful and morbidity/ mortality is minimal.
\end{abstract}

Key words: septic shock, dialysis, Ogilvie syndrome.

Acute colonic pseudo-obstruction (ACPO) is also known as Ogilvie's syndrome after Sir Heneage Ogilvie who first reported the condition in $1948^{1}$. It is characterized by massive colonic distension in the absence of mechanical obstruction (80-90\%), abdominal pain (80\%), abdominal tenderness (62\%), nausea and/or vomiting $(60 \%)$, obstipation $(40 \%)$, and fever $(37 \%) .{ }^{2}$ The exact pathophysiology is not fully understood, but if it is untreated the distension can result in rupture or ischemic perforation of the bowel. Ischemic bowel results in tissue damage or death in the affected portion of the bowel. Individuals with a perforated or ischemic bowel have a greater incidence of fever and may have signs of inflammation of the peritoneum (peritonitis). Despite the rare occurrence in children, Ogilvie syndrome should be remembered in a child with abdominal distention

\section{Case Report}

A 10-year-old child with an unremarkable past history presented to the pediatric intensive care unit with vomiting, diarrhea, fever, unconsciousness and respiratory failure. There was a history of constipation for two years. He was admitted to pediatric gastroenterology department and his laboratory tests and physical examinations were normal. Some drugs were written for constipation and he did not come for control again. Family history was negative for abnormal gastrointestinal motility, autonomic dysfunction, and mitochondrial defects. He was entubated because of the respiratory failure. We detected pleural effusion on his chest $\mathrm{X}$-ray. His blood pressure at the admission was $50 / 30 \mathrm{mmHg}$. We loaded $20 \mathrm{ml} / \mathrm{kg}$ saline three times and started to feel his femoral pulse and added norepinephrine $(0.1 \mu \mathrm{g} / \mathrm{kg} / \mathrm{min})$ to the therapy. Laboratory analysis revealed: white blood cell count $26,520 / \mathrm{mm}^{3}$, hemoglobin 17.4 $\mathrm{g} / \mathrm{dl}$, platelet count $209,000 / \mathrm{mm}^{3}$, C-reactive protein $243 \mathrm{mg} / \mathrm{L}$, erythrocyte sedimentation rate $2 \mathrm{~mm} / \mathrm{h}$, procalcitonin $100 \mathrm{ng} / \mathrm{ml}, \mathrm{BUN}$ $59.9 \mathrm{mg} / \mathrm{dl}$, creatinine $1.77 \mathrm{mg} / \mathrm{dl}$, sodium $147 \mathrm{mEq} / \mathrm{L}$, potassium $5.8 \mathrm{mEq} / \mathrm{L}$, calcium $6.5 \mathrm{mg} / \mathrm{dl}$; phosphorus $6.7 \mathrm{mg} / \mathrm{dl}$, magnesium, $1.8 \mathrm{mg} / \mathrm{dl}$, albumin $1.9 \mathrm{~g} / \mathrm{dl}$, amylase $33 \mathrm{U} / \mathrm{L}$, lipase $9 \mathrm{U} / \mathrm{L}$, alanine aminotransferase was 235 $\mathrm{U} / \mathrm{L}$, g-glutamyl transpeptidase $93 \mathrm{U} / \mathrm{L}$, lactate dehydrogenase $988 \mathrm{IU} / \mathrm{L}$. Stool evaluation for $C$. difficile toxin and stool guaiac test results were negative. Lactate level in blood gas analysis was $7.6 \mathrm{mmol} / \mathrm{L}$. Calcium gluconate infusion $(50$ $\mathrm{mg} / \mathrm{kg} /$ day) was added to therapy. Blood, urine, pleural fluid, fungal, and bacterial cultures were negative. Echocardiogram was normal with no coronary artery involvement. Tests for adenovirus and rotavirus were negative. He had abdominal distension and increasing volume 
of bilious nasogastric aspirate so abdominal computed tomography (CT) was planned. An abdominal radiograph and $\mathrm{CT}$ scan revealed massive dilation of the colon and rectum (Fig. 1, 2). Minimal fluid was detected in the abdomen. Rectal examination showed ballooning of the rectum without fecal impaction. He was operated by pediatric surgery and there was no ischemia or perforation in the gastrointestinal system. A biopsy was performed from colon for the short segment Hirschsprung disease; but biopsy result was clear. The diagnosis of Ogilvie syndrome was entertained because of massive abdominal distension with preferential colonic dilation without signs of mechanical obstruction or perforation. The child was managed conservatively with nasogastric tube and rectal tube insertion for decompression, electrolyte correction, intravenous fluid replacement, urinary catheterization to monitor urine output, antibiotics and analgesic medications. His condition deteriorated with increasing abdominal distension. Alanine aminotransferase and aspartate aminotransferase increased because of the liver failure and we added $\mathrm{N}$-acetyl cysteine to the therapy for hepatic regeneration. Due to the disseminated intravascular coagulation and liver failure, prothrombin time (PT) and active partial prothrombin time (aPTT) increased. Fresh frozen plasma and vitamin-K were administered. In his followup, his urine output began to decrease (< $0.5 \mathrm{ml} / \mathrm{kg} / \mathrm{h}$ ). We performed continuous renal replacement therapy (CRRT) because he was hemodinamically unstable. CRRT was ended because the filter was clotted. So, intermittent

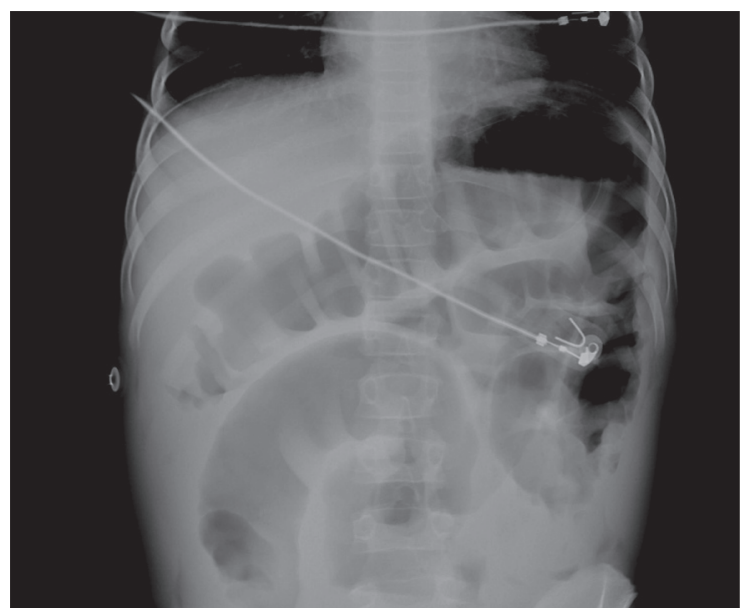

Fig. 1. Abdominal radiograph shows massive small and large bowel dilation. hemodialysis had to be instituted. On the 10th day of hospitalization we stopped intermittent hemodialysis and his urine output increased. The patient began to feed; on the 21st day of hospitalization, the conservative therapy was ended and he was discharged.

A written informed consent was obtained from the parents of the patient for publication.

\section{Discussion}

Ogilvie syndrome is a rare, acquired disorder characterized by abnormalities affecting the involuntary, rhythmic muscular contractions (peristalsis) within the colon. It is seen in the adult population, but rarely in children..$^{3-5}$ This syndrome occurs in patients with serious medical and surgical illnesses including stroke, myocardial infarction, neoplasia, metabolic disturbances, spinal injury, peritonitis, sepsis, and shock, and with various medications such as narcotics, tricyclic antidepressants, and sedatives or hypnotics. ${ }^{6}$ Our case presented with septic shock including hypotension, prolonged capillary refill time, decreased urine output $(<0.5 \mathrm{ml} / \mathrm{kg} / \mathrm{h})$, metabolic acidosis, liver failure and respiratory failure. Mechanical obstruction, perforation, and ischemia are to be excluded before the diagnosis is made. Unfortunately, we confirmed our definition with surgical intervention.

The diagnosis of Ogilvie syndrome is based on history, physical and radiological examination, and exclusion of other diagnoses. There are no specific laboratory tests but the plain abdominal radiographs are the most useful diagnostic tool for this disorder. Further, there is no clear established criteria for pediatric population.

Therapeutic options include supportive therapy, medications, decompression and surgery. Specific

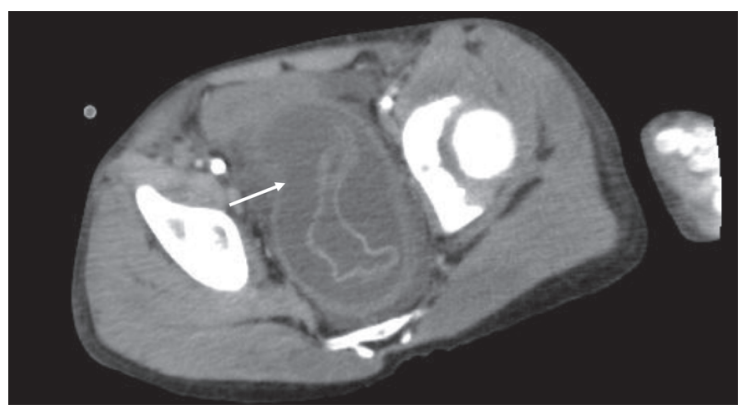

Fig. 2. Dilatation of the right hemicolon extending to the rectum (white arrow). 
therapeutic procedures and interventions may vary, depending upon numerous factors, such as disease progression; the presence or absence of certain symptoms; the status of the bowel; an individual's age and general health; and/ or other elements. Successful resolution is achieved in $83-96 \%$ of patients within 2-6 days of initiating therapy. ${ }^{7}$ Inharmoniously with the literature the recovery period of our case was longer. We had delayed response in our conservative treatment. We thought that this situation was associated with septic shock and related to multi-organ failure such as liver and kidney. In follow-up we had to start CRRT. Rectal tube placement is also helpful if the colonic distention extends to the rectosigmoid region as occurred in our patient.

Studies have shown the use of pharmacological agents like erythromycin and neostigmine in the management of Ogilvie syndrome. ${ }^{8-11}$ But we did not use this medication because the experience of neostigmine in the pediatric age group is limited. ${ }^{5}$

In our patient septic shock contributed to Ogilvie syndrome. If we can suspect and diagnose early, supportive management is successful and morbidity/mortality is minimal.

\section{REFERENCES}

1. Ogilvie WH. Large intestine colic due to sympathetic deprivation: A new clinical syndrome. Br Med J 1948; 2: 671-673.

2. Vanek VW, Al-Salti M. Acute pseudo-obstruction of the colon (Ogilvie's syndrome). An analysis of 400 cases. Dis Colon Rectum 1986; 29: 203-210.

3. Vadala G, Santonocito G, Mangiameli A. Ogilvie's syndrome. Minerva Med 1998; 89: 185-188.

4. Irabor DO, Ladipo JK, Ogunsanya WF, Akra G, Oladoyin O, Aimakhu C. Ogilvie's syndrome (colonic pseudoobstruction) occurring in an 18-year-old Nigerian female. West Afr J Med 2001; 20: 75-77.

5. Gmora S, Poenaru D, Tsai E. Neostigmine for the treatment of pediatric acute colonic pseudo-obstruction. J Pediatr Surg 2002; 37: 1-3.

6. Peck SN, Altschuler SM. Pseudo-obstruction in children. Gastroenterol Nurs 1992; 14: 184-188.

7. MacColl C, MacCannell KL, Baylis B, Lee S. Treatment of acute colonic pseudoobstruction (Ogilvie's syndrome) with cisapride. Gastroenterology 1990; 98: 773-776.

8. Fazel A, Verne GN. New solutions to an old problem: acute colonic pseudo-obstruction. J Clin Gastroenterol 2005; 39: 17-20.

9. Stephenson BM, Morgan AR, Salaman JR, Wheeler MH. Ogilvie's syndromea new approach to an old problem. Dis Colon Rectum 1995; 38: 424-427.

10. Turégano-Fuentes F, Muñoz-Jiménez F, Del ValleHernández E, et al. Early resolution of Ogilvie's syndrome with intravenous neostigmine: a simple effective treatment. Dis Colon Rectum 1997; 40: 1353-1357.

11. Rovira A, Lopez A, Cambray C, Gimeno C. Acute colonic pseudoobstruction (Ogilvie's syndrome) treated with erythromycin. Intens Care Med 1997; 23: 798. 